\title{
PDC Analysis of LLDPE-NR Nanocomposite for Effect of Moisture Absorption
}

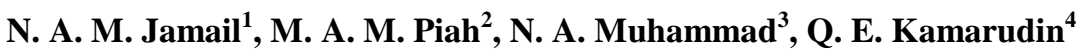 \\ ${ }^{1}$ Faculty of Electrical and Electronic Engineering, Universiti Tun Hussein Onn Malaysia, \\ 86400 Parit Raja, Batu Pahat, Johor, Malaysia \\ ${ }^{2}$ Institute of High Voltage and High Current (IVAT), Faculty of Electrical Engineering, Universiti Teknologi Malaysia, \\ 81310, Skudai, Johor, Malaysia \\ ${ }^{3}$ School of Electrical and Electronic Engineering, Engineering Campus, Universiti Sains Malaysia, \\ 14300 Nibong Tebal, Penang, Malaysia \\ ${ }^{4}$ Faculty of Mechanical and Manufacturing Engineering, Universiti Tun Hussein Onn Malaysia (UTHM), \\ 86400 Batu Pahat, Johor, Malaysia
}

\section{Article Info}

Article history:

Received Aug 5, 2017

Revised Oct 28, 2017

Accepted Nov 14, 2017

\section{Keyword:}

Depolarization current

LLDPE-NR

Moisture content

Polarization current

Polymer nanocomposite

\begin{abstract}
The properties of insulation have been improved by many research and the ability of nanocomposite material that composes the characteristic of improving electrical performance due to the addition of nanofiller into the based material gets serious attention. Polarization and Depolarization Current (PDC) measurement that has the ability to assess the condition of HV insulations with the initial periods after a DC step voltage application was favoured compared to other non-destructive monitoring techniques. This paper presents the works on moisture absorption in LLDPE-NR nanocomposite with different amount and percentage of nanofillers. The study of PDC level of the LLDPE-NR compound, filled with different amount of $\mathrm{SiO}_{2}, \mathrm{TiO}_{2}$ and MMT nanofiller using Polarization and Depolarization Current (PDC) measurement technique is the main objective of this research. These results show that sample A1 has the lowest polarization current value and sample B5 has the lowest depolarization current value.
\end{abstract}

Copyright (C) 2017 Institute of Advanced Engineering and Science. All rights reserved.

\section{Corresponding Author:}

N. A. M. Jamail,

Faculty of Electrical and Electronic Engineering,

Universiti Tun Hussein Onn Malaysia,

86400 Parit Raja, Batu Pahat, Johor, Malaysia.

Email: norakmal@uthm.edu.my

\section{INTRODUCTION}

Some research has been done to study on moisture absorption of polymer nanocomposite at different level of water content [1-4]. They have discussed on how the water absorption by nanofiller can significantly affect the material electrical properties. Researchers [5], [6] have tested pure epoxy and epoxy composites thermal properties, moisture absorption and dielectric properties using micron-sized and nano-sized filler. The nano composite has a higher moisture absorption compared to microcomposite from the test results obtained. The filter density, shape and the surface treatment influence the result produced. The dielectric constant ratio and degree of interaction between filler and polymer represents the effective dielectric constant of composite. The Interphase dielectric constant can be increased by the addition of silane coupling agent which could form the chemical bonding and improves the interface interaction in the composite that could be obtained from the experimental data and molecular dipole polarization calculations [5].

Researcher [7] has done the analysis of PDC measurement for cables. This is a case of severe thermal aging. High temperature indicates that the cable was in aging and fault condition. It can be seen that 
the conductive contaminants especially free water subject to high conduction current. The improvement can be seen when the result of polarization and depolarization current obtained is lower than the result before changes being made. Polarization and depolarization current measurement can be used to monitor the aging effect due to moisture.

Research had been done on LLDPE-NR nanocomposite using PDC for normal condition [8], [9] and effect of electrical tracking[10], [11]. These researches show that different type of nanofiller gives different level of PDC patern. Effect of electrical tracking shows higher PDC value compared with normal condition.

\subsection{Sample Preparation}

Brabender mixer with chamber size of $50 \mathrm{~cm} 3$ was used to prepare polyethylene nanocomposites by melting and mixing it under $170^{\circ} \mathrm{C}$. The screw speed that rotates at $35 \mathrm{rpm}$ with the mixing time of $2 \mathrm{~min}$ was controlled by the mixer which possesses higher shear force. A circle shaped polymer nanocomposites were mold with the diameter of $7.5 \mathrm{~cm}$ and the thickness of $3 \mathrm{~mm}$ by hot melting by exerting the pressure of 1 ton under $170^{\circ} \mathrm{C}$. This process was carry out for $10 \mathrm{~min}$ by varying the concentrations of nanofiller with $1,3,5$ and $7 \%$ wt respectively. Table 1 shows the compound formulations and designation.

Table 1. Compound formulations and designation

\begin{tabular}{|c|c|c|c|c|}
\hline \multirow{3}{*}{ Test Sample } & \multicolumn{3}{|c|}{ Constituents Composition \% wt } & \multirow{3}{*}{ Designation } \\
\hline & & Natural & & \\
\hline & LLDPE & $\begin{array}{l}\text { Rubber } \\
\text { (SMR CV 60) }\end{array}$ & Nanofiller & \\
\hline \multirow{2}{*}{$\begin{array}{l}\text { Unfilled } \\
\text { LLDPE }\end{array}$} & 80 & 20 & 0 & $\mathrm{R}$ \\
\hline & 80 & 20 & 1 & A1 \\
\hline LLDPE + & 80 & 20 & 3 & A3 \\
\hline Natural Rubber & 80 & 20 & 5 & A5 \\
\hline$+\mathrm{SiO}_{2}$ & 80 & 20 & 7 & A7 \\
\hline & 80 & 20 & 1 & $\mathrm{~B} 1$ \\
\hline \multirow{4}{*}{$\begin{array}{l}\mathrm{LLDPE}+ \\
\text { Natural Rubber } \\
+\mathrm{TiO}_{2}\end{array}$} & 80 & 20 & 3 & B3 \\
\hline & 80 & 20 & 5 & B5 \\
\hline & 80 & 20 & 7 & B7 \\
\hline & 80 & 20 & 3 & $\mathrm{C} 3$ \\
\hline LLDPE + & 80 & 20 & 5 & $\mathrm{C} 5$ \\
\hline $\begin{array}{l}\text { Natural Rubber } \\
+ \text { MMT }\end{array}$ & 80 & 20 & 7 & $\mathrm{C} 7$ \\
\hline
\end{tabular}

\section{RESEARCH METHOD}

\subsection{PDC Measurement Technique}

A dc voltage step was applied on the dielectric materials to measure the polarization current whereas by removing the dc voltage source incorporating with a switch which turn on to short circuit at the under tested objects [12-14] depolarization current was obtained. 1000V of dc voltage was applied continuously for about 10,000 seconds for polarization and depolarization time. The PDC measurement is shown in Figure 1. PDC testing was done at IVAT, UTM.

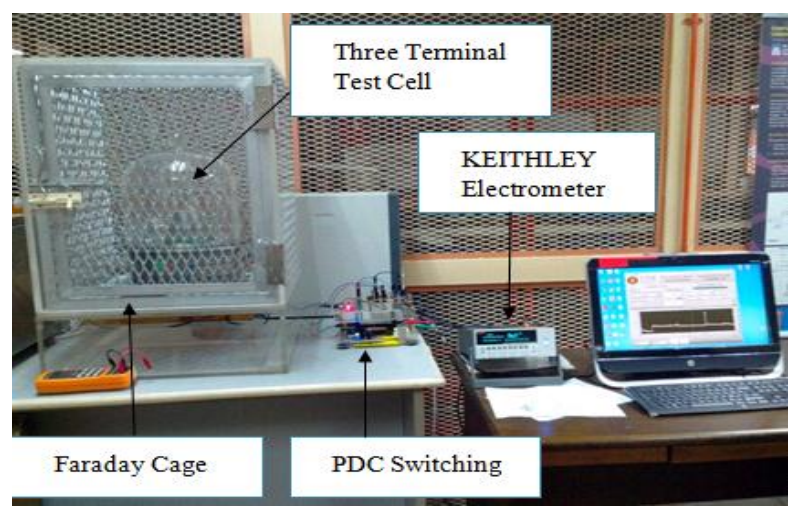

Figure 1. PDC testing 


\subsection{Moisture Absorption Test}

Samples of difference types and \% wt added of nanofilller are placed in separate container filled with distilled water as shown in Figure 2. Distilled water is used to avoid an influence of salts or impurities on the measurement results. To ensure the temperature does not influence the rate of absorption of water, each sample was placed in a room under the same temperature.

There are several possibilities to determine the water absorption of solid materials. The fastest and most simple method is to determine the specimens' mass increase by weighing. Prior to the water storage the mass $\mathrm{m}_{0}$ of each specimen is determined. During the 95 days water storage the specimen's mass increase $\Delta \mathrm{m}$ is determined in constant time intervals. The current moisture content $\mathrm{M}$ inside the specimens is calculated by $\mathrm{m}_{0}$ and the absorbed moisture $\Delta \mathrm{m}$.

$$
M=\frac{\Delta m}{m_{0}} \times 100 \%=\frac{m-m_{0}}{m_{0}} \times 100 \%
$$

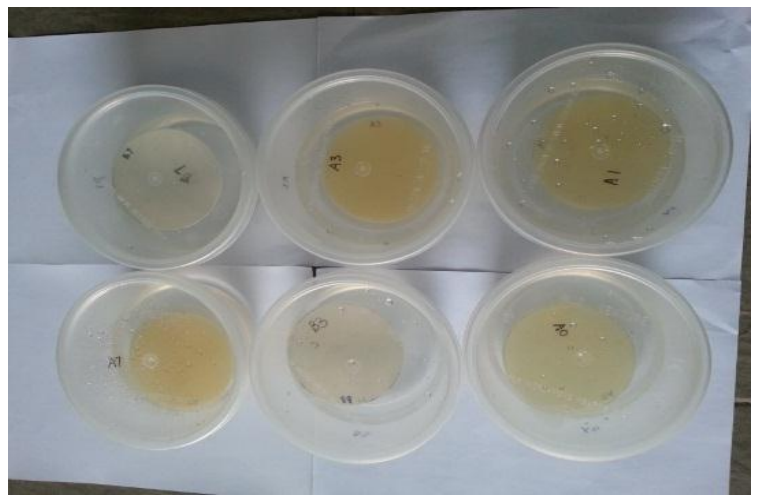

Figure 2. Sample immersed in distilled water

\section{RESULTS AND ANALYSIS}

\subsection{Moisture Absorption}

Table 2 shows the moisture absorption percentage of saturation for all samples. From the table, it shows that sample group $\mathrm{A}$ and $\mathrm{C}$ gives more moisture absorption effect for nanofiller more than $5 \%$ compared with sample group B. From the results obtained, it shows that LLDPE-NR/MMT sample give the highest moisture absorption effect compared with sample LLDPE-NR/SiO $\mathrm{S}_{2}$ and sample LLDPE-NR/TiO ${ }_{2}$. LLDPE-NR/MMT at 7\% of MMT shows the highest absorption rate of water compare to other samples. It was found that concentration of MMT nanofiller has increased the percentage of water absorption into LLDPE-NR nanocomposite. These results approved that MMT is reactive semiconductor filler and it is not good for dielectric application.

Table 2. Moisture absorption percentage of saturation

\begin{tabular}{|c|c|c|c|c|c|c|c|c|c|c|c|c|}
\hline Sample & $\mathrm{R}$ & A1 & A3 & A5 & A7 & B1 & B3 & B5 & B7 & C3 & C5 & C7 \\
\hline $\begin{array}{c}\text { Moisture } \\
\text { absorption } \\
\text { percentage } \\
(\%)\end{array}$ & 0.29 & 0.29 & 0.46 & 0.54 & 0.63 & 0.30 & 0.5 & 0.50 & 0.59 & 0.51 & 0.68 & 0.73 \\
\hline
\end{tabular}

MMT and $\mathrm{SiO}_{2}$ nanofiller is hydrophilic hydroxyl characteristic groups. They tend to absorbed more water compared with $\mathrm{TiO}_{2}$ nanofiller. LLDPE-NR/MMT and LLDPE-NR/SiO 2 sample at $7 \%$ wt nanofiller showed dramatic increase in moisture uptake. This can be due to hydrophilic nature of the nano-sized MMT and silica surface tend to attract moisture.

The enlarge size of the hydrated ion may inhibit its migration through the limited free space in the solid dielectric. The hydrated ions may penetrate the composite dielectric by migration through the available free space as in a homogeneous specimen. However, in a composite specimen, the possibility exists that the water may migrate via the interfaces between the component parts. 


\subsection{Polarization Current}

Figure 3 shows polarization current trends for samples after 95 days immersed in water for sample $\mathrm{R}$ and samples group A. It is shown that sample A1 has lowest polarization current in group A. Sample A1 shows the lowest moisture absorption rate compare to the others compounds as there is only $0.29 \%$ moisture absorption before getting saturated.

Figure 4 shows polarization current trends effect of moisture absorption for sample group B. It is shown that sample B5 has lowest polarization current in group B. Sample B5 absorp water only $0.5 \%$ for it to be saturated. Even though sample B5 has higher effect of water absorption, it still has lowest polarization current compared with sample B1 which has lowest absorption rate. It shows that hydrophobic characteristic of $\mathrm{TiO}_{2}$ nanofiller will not affect the dielectric properties of LLDPE-NR/TiO 2 due to moisture absorption.

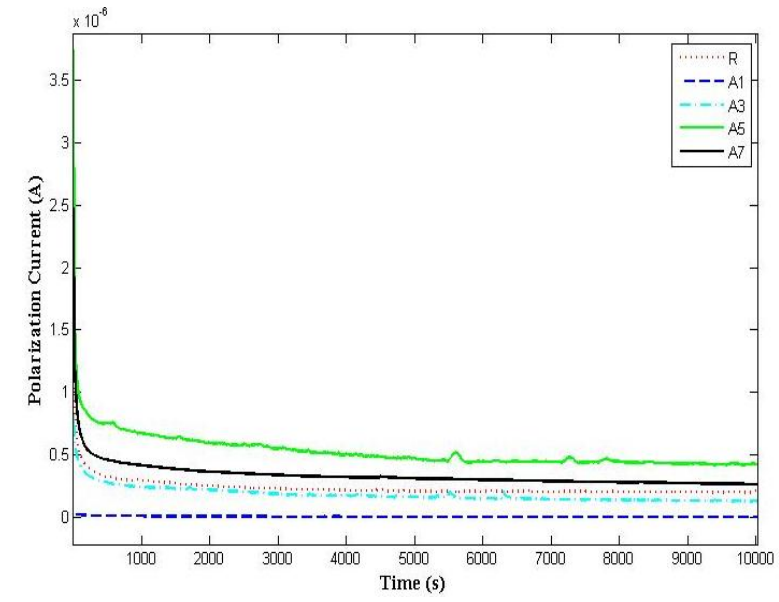

Figure 3. Polarization current pattern for sample R, A1, A3, A5 and A7 after water absorption

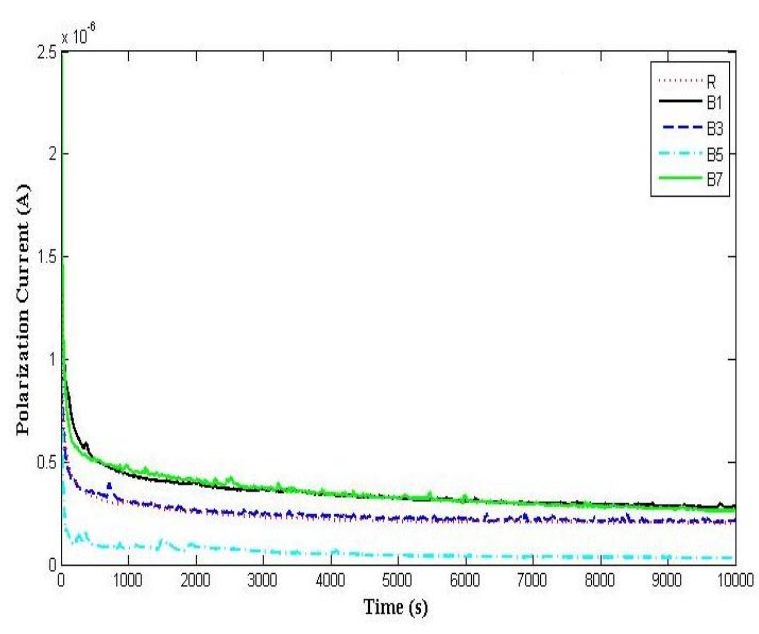

Figure 4. Polarization current pattern for sample B1, $\mathrm{B} 3, \mathrm{~B} 5$ and $\mathrm{B} 7$ after water absorption

Figure 5 shows polarization current trends effect of moisture absorption for sample group C. It is shown that sample C3 has lowest polarization current in group C. Sample C3 shows the lowest moisture absorption rate compare to the others compounds as there is only $0.51 \%$ moisture absorption before getting saturated.

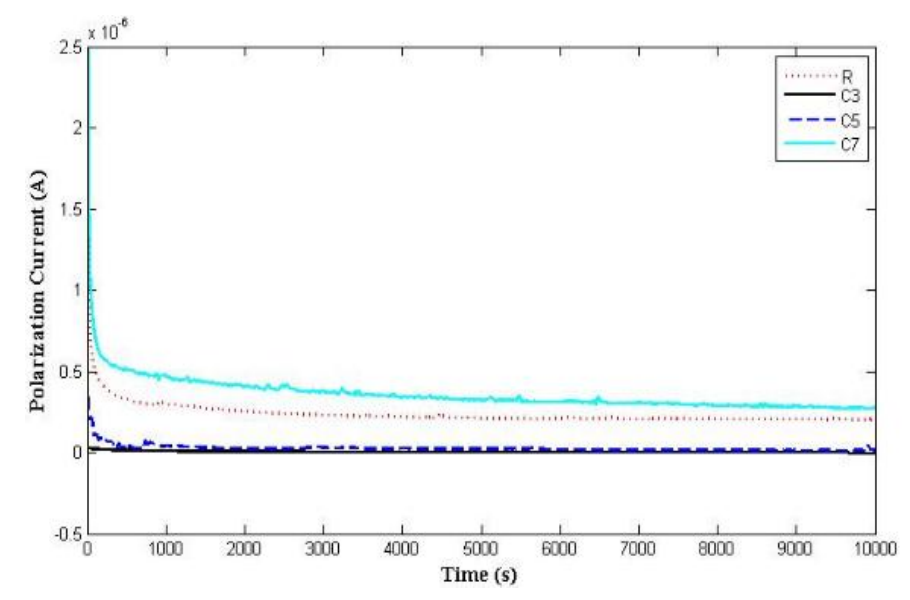

Figure 5. Polarization current pattern for sample C3, C5 and C7 after water absorption

\subsection{Depolarization Current}

Figure 6 shows depolarization current trends for samples after 95 days immersed in water for sample R and samples group A. It is shown that sample A1 has lowest depolarization current in group A. 
Figure 7 shows depolarization current trends effect of moisture absorption for sample group B. It is shown that sample B5 has lowest depolarization current in group B.

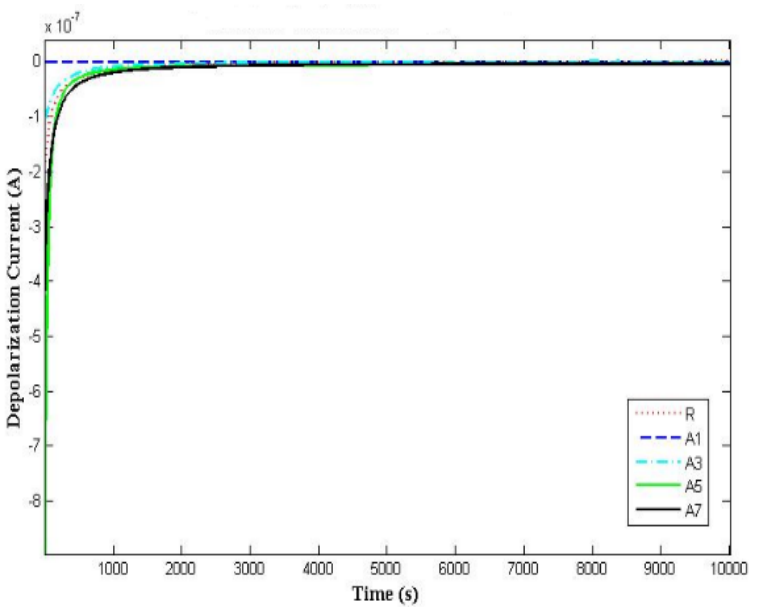

Figure 6. Depolarization current pattern for sample $\mathrm{R}, \mathrm{A} 1, \mathrm{~A} 3, \mathrm{~A} 5$ and $\mathrm{A} 7$ after water absorption

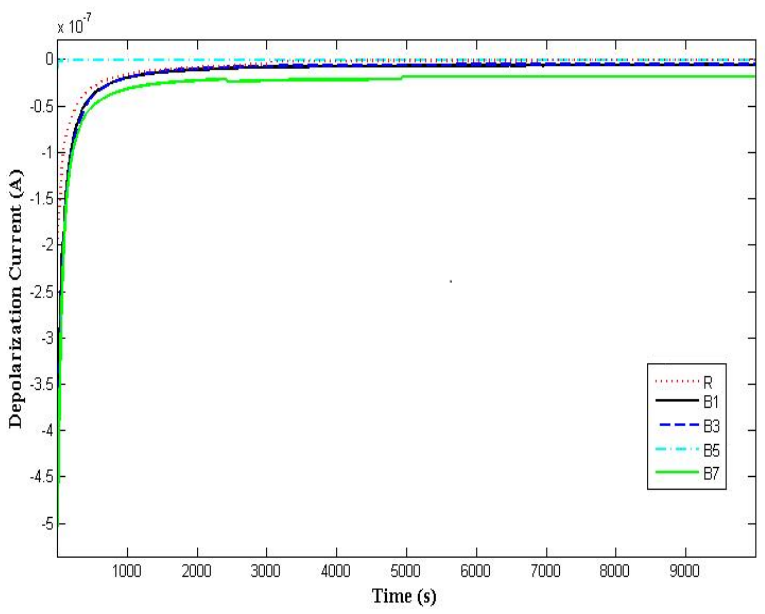

Figure 7. Depolarization current pattern for sample B1, B3, B5 and B7 after water absorption

Figure 8 shows depolarization current trends effect of moisture absorption for sample group C. It is shown that sample C5 and C7 show the lowest depolarization current.

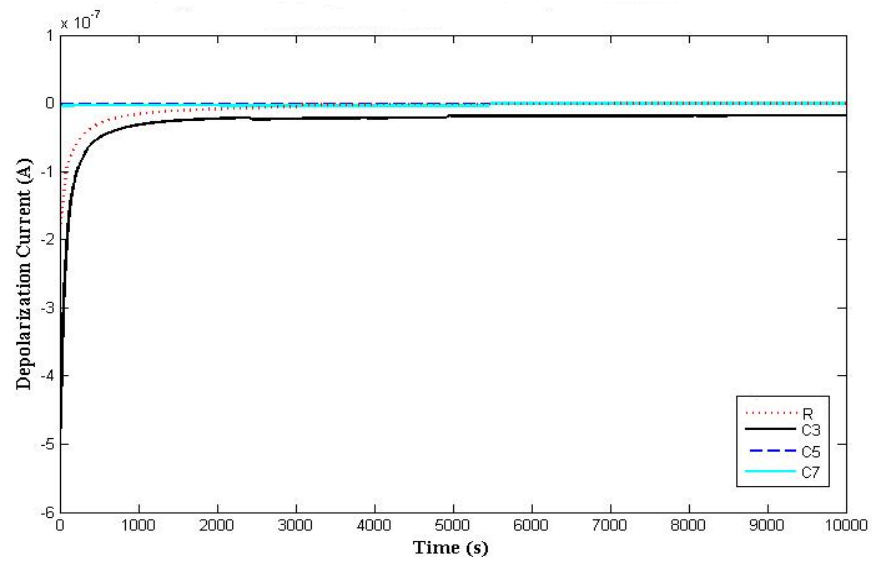

Figure 8. Depolarization current pattern for sample C3, C5 and C7 after water absorption

It clearly shows the depolarization current is small and getting close to zero axes in the time range from 1000 to $10000 \mathrm{~s}$. It means that the nanofiller could suppress depolarization current in LLDPE-NR after introduction of nanofiller. The variation of depolarization current is not distinct with the increase of nanofiller concentration for normal and moisture absorption effect.

\section{CONCLUSION}

Results show that sample A1 has the lowest polarization current and sample B5 has the lowest depolarization current value. These samples contribute to the best sample due to lowest PDC values for effect of moisture absorption. Hydrophobic filler contributes to lower moisture absorption, particularly in the interfacial regions between fillers and polymer matrix and thus effect the composite dielectric response. Besides that, quality dispersion of nanofiller and the presence of absorbed moisture also contribute to dielectric response changes. 


\section{ACKNOWLEDGEMENTS}

The authors gratefully acknowledge the Universiti Tun Hussein Onn Malaysia, Power and Renewable Energy Team (PaRENT), High Voltage Laboratory UTHM and IVAT Universiti Teknologi Malaysia for the equipment support and Taiko Plantation Sdn Bhd as a supplier of Natural Rubber.

\section{REFERENCES}

[1] Chen, Z, Fothergill, J.C, and Rowe, S.W, "The effect of water absorption on the dielectric properties of epoxy nanocomposites," Dielectrics and Electrical Insulation, IEEE Transactions on, 2008. 15(1): p. 106-117.

[2] Lau, K. Y., Vaughan, A. S., Chen, G. and Hosier, I. L., "Dielectric response of polyethylene nanocomposites: The effect of surface treatment and water absorption," In Electrical Insulation and Dielectric Phenomena (CEIDP), 2012 Annual Report Conference on. 2012.

[3] Bernier, S., Drapeau, J. F., Jean, D. and David, E., "The effect of water ingress on dielectric properties of polyethylene cable insulation," In Electrical Insulation (ISEI), Conference Record of the 2012 IEEE International Symposium on. 2012.

[4] Fabiani, D., Montanari, G. C., Testa, L., Schifani, R., Guastavino, F., Bellucci, F. and Deorsola, F., "Effect of water adsorption on the dielectric properties of polymer nanocomposites," In Electrical Insulating Materials, 2008. (ISEIM 2008). International Symposium on. 2008.

[5] Sun Y, Zhang, Z., and Wong, C.P. "Influence of interphase and moisture on the dielectric spectroscopy of epoxy/silica composites," Polymer, 2005. 46(7): pp. 2297-2305.

[6] Sami, A., Frechette, M. F., David, E. and Savoie, S., "Water as a Digression Relative to the Dielectric Response in the Frequency Domain for Polymer Composites," In Electrical Insulation and Dielectric Phenomena, 2008. CEIDP 2008. Annual Report Conference on. 2008.

[7] Bhumiwat, S.A., "On-site non-destructive diagnosis of in-service power cables by Polarization / Depolarization Current analysis," In Electrical Insulation (ISEI), Conference Record of the 2010 IEEE International Symposium on. 2010

[8] Jamail N.A.M., M.A.M. Piah, and N.A. Muhamad, "Effects of $\mathrm{SiO}_{2}$ nanofillers on Polarization and Depolarization Current (PDC) of LLDPE-NR nanocomposite insulating materials", in Power and Energy (PECon), 2012 IEEE International Conference on. 2012.

[9] Jamail N.A.M, M.A.M. Piah, N.A. Muhamad, R.A. Zainir, N. F. Kasri, Q.E. Kamarudin, "Polarization And Depolarization Current Measurement of Polymer Added with Nano-Particles of Silicon Oxide for Hv Insulation," Jurnal Teknologi, 2013, vol. 64, no. 4, pp: 141-144

[10] Nor Akmal Mohd Jamail , Mohamed Afendi Mohamed Piah, Nor Asiah Muhamad, Rubiatul Addawiyah Zainir, Nur Faizal Kasri, "Effects of $\mathrm{SiO} 2$ and $\mathrm{TiO} 2$ Nanofillers on Conductivity Level of LLDPE-NR Nanocomposite HV Insulator," Applied Mechanics and Materials Journal, vol. $284-287$, pp:305-309

[11] Jamail N. A. M, M. A. M. Piah , F. L. Muhamedin, N. F. Kasri, N. A. Muhamad, Q. E. Kamarudin, "Electrical Tracking Characterization of LLDPE-Natural Rubber Blends Filled with Nanofillers", 2013 IEEE Conference on Electrical Insulation and Dielectric Phenomena, 20 - 23 Oktober 2013, Shenzhen, CHINA

[12] Saha T. K. and P. Purkait, "Investigation of polarization and depolarization current measurements for the assessment of oil-paper insulation of aged transformers, Dielectrics and Electrical Insulation," IEEE Transactions on, vol. 11, pp. 144-154, 2004.

[13] Saha T. K., et al., "Optimal Time Selection for the Polarisation and Depolarisation Current Measurement for Power Transformer Insulation Diagnosis," in Power Engineering Society General Meeting, 2007. IEEE, 2007, pp. 1-7.

[14] Saha T. K. and P. Purkait, "Investigation of an expert system for the condition assessment of transformer insulation based on dielectric response measurements," Power Delivery, IEEE Transactions on, vol. 19, pp. 1127-1134, 2004.

\section{BIOGRAPHIES OF AUTHORS}

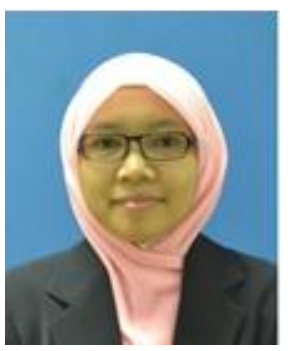

Nor Akmal Mohd Jamail is a lecturer of Universiti Tun Hussein Onn Malaysia since 2008. She received the Bachelor degree in Electrical Engineering from Universiti Teknologi Malaysia in 2005, M.Eng in Power System from Universiti Tun Hussein Onn Malaysia in 2007 and Ph.D. in High Voltage Engineering from Universiti Teknologi Malaysia, in 2015. Her research interests include condition monitoring of polymer nanocomposite insulation for HV purpose, dielectrics and electrical insulation. She is registered with the Board of Engineers Malaysia (BEM). 


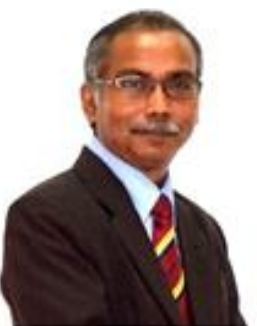

Dr. Mohamed Afendi Mohamed Piah (M.A.M. Piah) is an associate professor at Faculty of Electrical Engineering, Universiti Teknologi Malaysia and a fellow member of the Institute of High Voltage and High Current (IVAT). He is also a Signatory of High Voltage Testing accreditation lab of ISO/IEC 17025. He received the B.Elect. Eng. degree from Universiti Teknologi Malaysia in 1986, M.Sc in Power System from University of Strathclyde, UK in 1990 and $\mathrm{PhD}$ in High Voltage Engineering from Universiti Teknologi Malaysia in 2004. He was appointed as an assistant director (Test and Calibration Division) of IVAT from 1996-2000 and Deputy Director of IVAT from 2007-2009. He has been involved in testing and calibration of high voltage equipments. His research interests include high voltage insulation diagnostic and co-ordination, electrical discharges, polymer nanocomposites insulating materials and insulator condition monitoring.

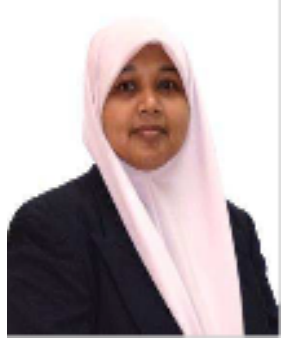

Nor Asiah Muhamad (M'13) is currently serving as Senior Lecturer at the School of Electrical and Electronic Engineering, Universiti Sains Malaysia. Previously, she was a researcher and senior lecturer at the Institute of High Voltage and High Current (IVAT) in Faculty of Electrical Engineering, Universiti Teknologi Malaysia, for 13 years. She obtained her Ph.D. degree in 2009 from University of New South Wales, Australia. She received her Bachelor's degree in Electrical and Electronic Engineering from Universiti Teknologi Petronas, Malaysia, in 2002 and Master's degree in Electrical Power Engineering from University of South Australia in 2006. Her research interest is centred on power system equipment monitoring, in particular, insulation diagnosis and the development of new systems for condition monitoring.

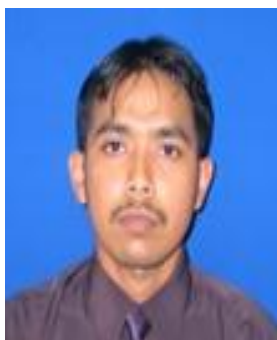

Qamarul Ezani Kamarudin is an instructor of Universiti Tun Hussein Onn Malaysia since 2007. He received the Bachelor degree in Mechanical Engineering from Universiti Teknologi Malaysia in 2006. His research interests include wind turbine and wind energy harvesting technique and polymer nanocomposite insulation material. He is registered with the Board of Engineers Malaysia (BEM). 